
ЗАМЕСТИТЕЛЬНОЙ ТЕРАПИИ МЕТАДОНОМ У ПОТРЕБИТЕЛЕЙ ИНЪЕКЦИОННЫХ НАРКОТИКОВ С ВИЧ-ПОЗИТИВНЫМ СТАТУСОМ, ИНФИЦИРОВАННЫХ ВИРУСОМ ГЕПАТИТА С, В Г. МИНСКЕ ${ }^{1}$ М. А. Шилова, ${ }^{2}$ А. В. Абрамович, 'И. Н. Вальчук, 'М. Л. Доценко, ${ }^{1}$ Г. Н. Чистенко, ${ }^{1}$ С. В. Жаворонок 'Белорусский государственный медицинский университет, Минск, Беларусь ${ }^{2}$ Городской клинический наркологический диспансер, Минск, Беларусь

Введение. В 2019 г. более 7,6 тыс. человек состояли на диспансерном наблюдении наркологической службы Республики Беларусь. Многие потребители инъекционных наркотиков (ПИН) инфицированы ВИЧ, вирусом гепатита C (ВГС) и являются источниками инфицирования для популяции.

Цель исследования - анализ эпидемиологических характеристик ПИН Республики Беларусь и г. Минска, оценки эфффективности проведения заместительной терапии метадоном (ЗМТ) в г. Минске в 2015-2019 г2. и возможных взаимодействий лекарственных средств при сочетанной терапии ВИЧ и ВГС на фроне ЗМТ.

Материал и методы. Для анализа использовались данные фрорм статистической отчетности УЗ «Городской клинический наркологический диспансер» г. Минска (N=5396) и деятельности кабинетов ЗМТ г. Минска $(N=161)$ за 2015-2019 ге. Полученные данные обработаны с помощью статистических программ Microsoft Excel 2010, $R$.

Результаты. Установлено, что удельный вес женщин среди ПИН в Республике Беларусь и в г. Минске не превышал 20\%. Среди ПИН доминировали лица 26-30 лет (23,07\% по нашей республике, 33,27\% - в г. Минске), со средним образованием (47 и 55,11\%, соответственно), холостые/незамужние лица (54 и 53,39\%, соответственно). Удельный вес ВИЧ-позитивных участников программы, коинфицированных ВГС, составляет 100,00\%, а среди принятых в программу ПИН доля участников с положительным ВИЧ статусом достоверно pacmem (Тпр. $=26,32 \%(p<0,05))$. Удельный вес участников программы ЗМТ, принимающих антиретровирусную терапию (АРТ), увеличился до 100,00\% (Cl 95,65-100,00, p<0,05) в 2019 2.

Выводы. Отсутствие воздействия противовирусной терапии ВГС лекарственными средствами (ЛС) прямого действия на фрармакокинетику и фрармакодинамику метадона может способствовать приверженности к заместительной терапии.

Ключевые слова: опиоиды, ПИН, наркопотребители, опиоидная заместительная терапия, ВИЧ, ВГС.

\title{
EPIDEMIOLOGICAL CHARACTERISTICS OF DRUG USE AND EFFECTIVENESS OF METHADONE SUBSTITUTION THERAPY IN HIV-POSITIVE INJECTING DRUG USERS INFECTED WITH VIRAL
}

HEPATITIS C IN MINSK

${ }^{1}$ M. A. Shylava, ${ }^{2}$ A. V. Abramovich, ${ }^{1}$ I. N. Valchuk, ${ }^{1}$ M. L. Dotsenko,

${ }^{1}$ G. N. Chistenko, ${ }^{1}$ S. V. Zhavoronok ${ }^{1}$ Belarusian State Medical University, Minsk, Belarus ${ }^{2}$ City Clinical Narcological Dispensary, Minsk, Belarus

Background. In 2019 more than 7.6 thousand people were under medical supervision of the drug addiction service of the republic. Many injecting drug users (IDUs) are infected with HIV and viral hepatitis C (HCV) and are the sources of infection for the population.

Objective - to analyze the epidemiological characteristics of IDUs of the Republic of Belarus and Minsk, to assess the effectiveness of methadone replacement therapy (MT) in Minsk in 2015-2019 and possible drug interactions in combination therapy for HIV and HCV in association with MT.

Material and methods. The data from statistical reporting forms of the City Clinical Narcological Dispensary of Minsk $(N=5396)$ and those of the activities of MT offices in Minsk $(N=161)$ for 2015-2019 were used for the analysis. The obtained data were processed using statistical programs Microsoft Excel 2010, R.

Results. It was found out that the proportion of women among IDUs in the republic and Minsk didn't exceed $20 \%$. Among IDUs are predominantly 26-30-year-olds (23.07\% in the republic, $33.27 \%$ in Minsk), individuals with secondary education (47\% and 55.11\% respectively), unmarried individuals (54\% and 53.39\% respectively). The share of HIV-positive program participants coinfected with viral hepatitis C (HCV) is $100.00 \%$ and among the IDUs admitted to the program, the proportion of participants with HIV-positive status is growing significantly (rate of increase is $26.32 \%$ 
$(p<0.05))$. The share of MT program participants taking antiretroviral therapy $(A R T)$ increased to $100.00 \%(C / 95.65-$ $100.00, p<0.05)$ in 2019.

Conclusions. The absence of the effect of direct-acting antivirals for the treatment of HCV on the pharmacokinetics and pharmacodynamics of methadone may contribute to replacement therapy adherence.

Keywords: opioids, IDUs, drug users, methadone replacement therapy, opioid replacement therapy, HIV, HCV.

Автор, ответственный за переписку:

Шилова Маргарита Александровна, канд. мед. наук, доц.

Белорусский государственный медицинский университет;

e-mail: makluk.sasha@gmail.com;

\section{Для цитирования:}

Эпидемиологическая характеристика наркопотребления и эффрективности проведения заместительной терапии метадоном у потребителей инъекционных наркотиков с ВИЧ-позитивным статусом, инфицированных вирусом гепатита С в г. Минске / М. А. Шилова, А. В. Абрамович, И. Н. Вальчук, М. Л. Доценко, Г. Н. Чистенко, С. В. Жаворонок // Гепатология и гастроэнтерология. 2020. Т. 4, № 1. С. 81-85. https://doi org/10.25298/2616-5546-2020-4-1-81-85
Corresponding author:

Shylava Marharyta Aleksandrovna, PhD (Medicine), Associate Professor; Belarusian State Medical University; e-mail: makluk.sasha@gmail.com

For citation:

Shylava MA, Abramovich AV, Valchuk IN, Dotsenko ML, Chistenko GN, Zhavoronok SV. Epidemiological characteristics of drug use and effectiveness of methadone substitution therapy in HIV-positive injecting drug users infected with viral hepatitis C in Minsk. Hepatology and Gastroenterology. 2020;4(1):81-85. https://doi.org/10.25298/2616-5546-2020-4-1-81-85

\section{Введение}

Потребление наркотических средств остается важной проблемой как для медицинского сообщества, так и для населения в целом. В 2017 г. число наркопотребителей в мире достигло $271 \mathrm{млн} \mathrm{человек,} \mathrm{а} \mathrm{более} 11$ млн человек употребляли наркотические вещества путем инъекций $[1,2]$. Растут и показатели смертности от наркопотребления (585 тыс. чел. в 2017 г.). Среди основных причин смерти и инвалидности можно выделить вирусный гепатит С (ВГС), ВИЧ-инфекцию и психические расстройства на почве употребления опиоидов. Общий ущерб от наркопотребления составил 42 млн потерянных лет «здоровой» жизни [1].

На начало 2019 г. под диспансерным наблюдением наркологической службы Республики Беларусь находилось 7,6 тыс. пациентов с синдромом зависимости от наркотических веществ и 5,1 тыс. пациентов, находящихся под профилактическим наблюдением в связи с употреблением наркотиков (не сопровождается клиническими проявлениями). По мнению ряда исследователей, истинное число потребителей инъекционных наркотиков (ПИН) в Беларуси может достигать 75-88,4 тыс. человек, так как не все представители данного сообщества попадают в поле зрения сотрудников правоохранительных органов и медицинских работников [3, 4].

Для ПИН характерно сочетание зависимости с рядом психических и соматических заболеваний, в том числе инфекций, передаваемых преимущественно парентеральным путем (ВГС, ВИЧ и др.) $[1,4,5]$. По данным литературных источников, каждый восьмой ПИН - носитель ВИЧ (1,4 млн мировой популяции) [1]. Распространенность ВИЧ среди ПИН в Беларуси в 2017 г. достигла 30,8\% при аналогичном показателе в популяции 0,2\% [5].

Таким образом, проблема наркопотребления и нарастание распространенности ВИЧ и ВГС среди ПИН остаются актуальными: не получая лечения, наркопотребители являются мощным резервуаром данных инфекций, а несоблюдение правил асептики и антисептики при употреблении наркотиков, в том числе опиоидов, путем инъекций, повторное и/или совместное использование одноразовых шприцев несколькими ПИН, «химический секс» приводят к распространению ВИЧ, ВГС и нарастанию числа инфицированных лиц.

Цель исследования - проанализировать возрастно-половые и социальные характеристики ПИН г. Минска, оценить эффективность проведения ЗМТ в г. Минске за 2015-2019 гг., динамику включения участников в программу заместительной терапии метадоном (ЗМТ), возможные взаимодействия лекарственных средств при сочетанной терапии ВИЧ и ВГС на фоне ЗМТ.

\section{Материал и методы}

Для анализа наркопотребления в г. Минске и эффективности работы программы ЗМТ использовались данные форм статистической отчетности УЗ «Городской клинический наркологический диспансер» (УЗ ГКНД) г. Минска $(\mathrm{n}=5396)$ и деятельности кабинетов ЗМТ г. Минска $(\mathrm{n}=161)$ с 2015 г. по 2019 г. В работе применялись методы эпидемиологической диагностики и статистического анализа. Полученные данные обработаны с помощью стандартных пакетов статистических программ Microsoft Excel 2010, R. Исследование проведено в соответствии с принципами экспериментальной и клинической биоэтики.

\section{Результаты и обсуждение}

В Республике Беларусь ЗМТ была организована в рамках пилотного проекта ВО3 (2007 г.) на базе Гомельского областного наркологического диспансера. С 2009 г. эта программа стала функционировать на базе УЗ ГКНД в г. Минске. На начало 2019 г. в Беларуси 728 пациентов с 
синдромом зависимости от опиоидов являлись участниками программы ЗТМ.

В 2019 г. в г. Минске 5396 потребителей психоактивных веществ (ПАВ) состояли на учете в УЗ ГКНД. 93,87\% из них больны наркоманией, a $6,13 \%$ - токсикоманы и потребители ПАВ. На диспансерном наблюдении состоит 3056 чел. (56,63\%): 54,86\% из них - наркопотребители, 1,78\% - лица, больные токсикоманией. На профрилактическом наблюдении состоит 43,37\% зависимых (39,01\% из них - потребители наркотических веществ).

В г. Минске в 2019 г. более половины наркопотребителей $(51,98 \%)$ употребляли опий («бубки», маковая соломка), 1,83\% - героин, 2,54\% - метадон, 13,97\% - каннабис, 0,74\% седативные средства, 11,68\% - психостимуляторы, 0,02\% галлюциногены. Полинаркоманией страдали 12,56\% наркопотребителей, а 1,48\% употребляли летучие растворители (клей «Момент» и др.). Курительные смеси употребляли $3,19 \%$ состоящих на официальном учете наркопотребителей. По данным УЗ ГКНД, употребления кокаина и насвая не зарегистрировано. Таким образом, от потребления опиоидов страдают более половины состоящих на учете наркопотребителей, что в свою очередь свидетельствует о высокой актуальности проблемы наркопотребления в г. Минске.

В Республике Беларусь среди лиц, состоящих на наркологическом учете, женщины составляют $17,38 \%$ (2,4 тыс. человек). При анализе полового состава наркопотребителей в г. Минске установлено, что 19,87\% из них - лица женского пола.

В Беларуси в возрастной структуре наркопотребителей наибольший удельный вес приходится на лиц 26-30 лет (3,2 тыс. человек, или 23,07\%), 31-35 лет (22,00\%), 21-25 лет (20,00\%). Аналогичная ситуация наблюдается и в г. Минске (возраст 26-30, 21-25 и 31-35 лет (33,27;

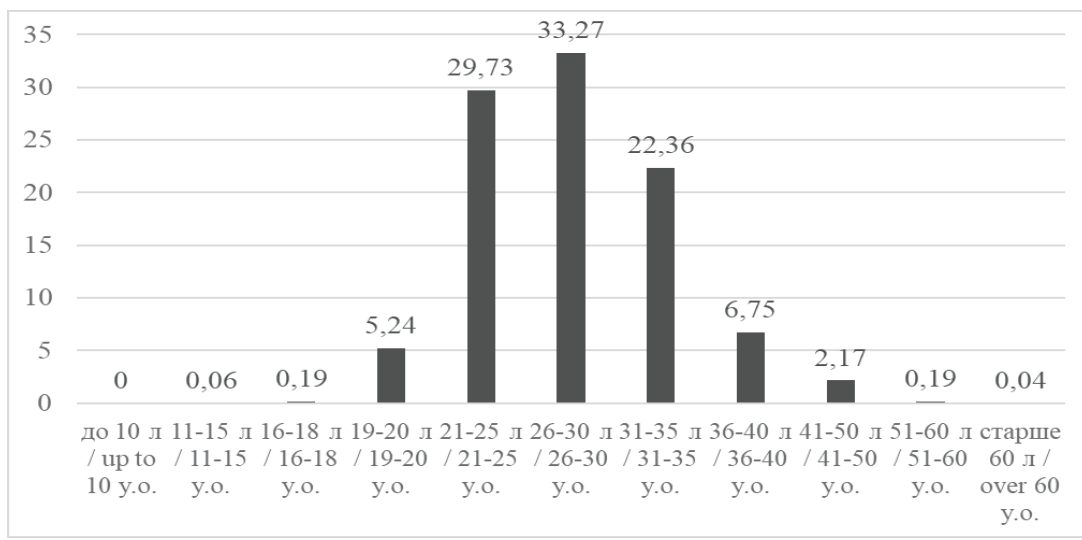

Рисунок 1. - Возрастная структура наркопотребителей в е. Минске в 2019 2.

Figure 1. - Age structure of drug users in Minsk in 2019
29,73 и 22,36\%, соответственно)) (рис. 1). Следует отметить, что лица данного возраста наиболее продуктивная и трудоспособная часть населения.

Наибольшее количество больных наркоманией и токсикоманией в Республике Беларусь имеют среднее образование - 47\% (6,5 тыс. человек). Среднее специальное образование имеют 39\% наркопотребителей, неполное среднее образование - 11\%, высшее - 2\%. В г. Минске по уровню образования среди наркопотребителей также доминируют лица со средним образованием. Их удельный вес $-55,11 \%$. Более 1/3 наркопотребителей - лица со средним специальным образованием $(35,73 \%)$. В социальной структуре наркопотребителей г. Минска преобладают работающие лица и лица, не имеющие работы, старше 20 лет. На их долю приходится 48,65 и $42,18 \%$, соответственно (рис. 2).

В зависимости от семейного положения наркопотребители в Беларуси распределены следующим образом: холост (не замужем) - 54\% (7,4 тыс. человек), женат (замужем) - 26\%, разведен (разведена) - 17\%, вдовец (вдова) - 3\%. В г. Минске в структуре наркопотребителей преобладают холостые (незамужние) лица (53,39\%), однако около 1/3 - женаты (замужем). Почти половина наркопотребителей г. Минска проживают с родителями (46,89\%) (рис. 3).

На территории Республики 34\% пациентов были судимы два раза и более (4,6 тыс. человек), однократно судимы - 25\% (3,3 тыс. человек), при этом судимость 34\% пациентов была связана с наркотиками [6]. В г. Минске доля осужденных наркопотребителей достигла 60,53\%, а $35,95 \%$ ПИН были судимы более 2 раз, причем у $32,60 \%$ судимость была связана с наркотиками. В течение 2019 г. 17,48\% наркопотребителей лечились стационарно.

Начиная с 2016 г., в Беларуси отмечается снижение обращаемости населения за оказанием наркологической помощи. Так, если в 2016 г. синдром зависимости от наркотических веществ впервые установлен у 679 пациентов, то в 2018 г. - у 439. Снижается и число обращений за анонимной помощью в УЗ ГКНД на территории г. Минска: с 2409 в 2012 г. до 505 в 2017 г. (в 4,8 раза). Основными причинами отказа от обращения к врачу-психиатру-наркологу были страх постановки на наркологический учет, боязнь попасть в поле зрения МВД (в т. ч. боязнь ареста и лишения свободы), социальная дискриминация со стороны 


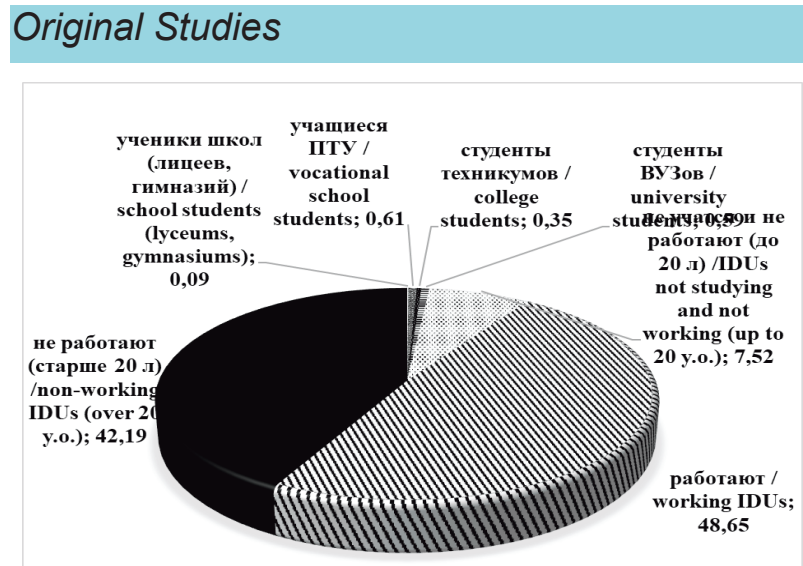

Рисунок 2. - Социальная структура наркопотребителей в 2. Минске (2019 г.)

Figure 2. - Social structure of drug users in Minsk (2019)

общества, отсутствие анонимности (по мнению респондентов) [7]

В начале 2019 г. в Беларуси 728 пациентов с синдромом зависимости от опиоидов были участниками программы ЗТМ. В г. Минске по состоянию на конец 2019 г. 478 ПИН были включены в программу ЗТМ (с 2009 г.), в т. ч. 198 ПИН с положительным ВИЧ-статусом (134 участника получали АРТ). С 2009 г. (начало функционирования программы в г. Минске) 57 ПИН возобновили ЗТМ, 49 из них были ВИЧ-инфицированными, 339 - выбыли из программы.

На территории г. Минска с 2015 г. по 2019 г. общая численность участников программы 3ТМ росла и колебалась в пределах 149 (2015 г.)-161 (2018 г.) участника. Каждый пятый участник программы - лицо женского пола (20,13-22,36\%), а в 2019 г. среди ВИЧ-позитивных участников программы удельный вес женщин достиг 26,37\%.

В г. Минске в анализируемом временном интервале отмечается достоверный рост числа ВИЧ-инфицированных участников программы (Тпр. $=26,32 \%(p<0,05))$, в т. ч. принимающих антиретровирусную терапию (АРТ) (Тпр.=30,00\% $(p<0,05)$ - их доля возросла до $100,00 \%$ (Cl 95,65-100,00, p<0,05) в 2019 г. Однако подбор дозы метадона на фоне АРТ при изменении или применении лекарственных средств (ЛС), снижающих/повышающих его концентрацию в крови (ненуклеозидные ингибиторы обратной транскриптазы и ингибиторы протеазы), рекомендуется проводить с применением лабораторного мониторинга концентрации метадона в плазме крови пациентов для предотвращения появления симптомов абстиненции [8].

Удельный вес ВИЧ-инфрицированных участников программы ЗТМ, коинфицированных ВГС, составил 100,00\%. По данным современных источников, метадон не вступает во взаимодействие с применяющимися для лечения ВГС ЛС

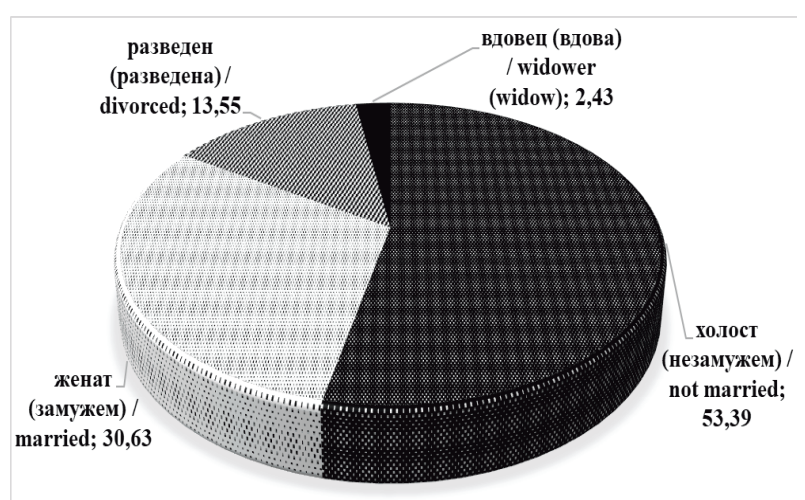

Рисунок 3. - Структура семейного положения наркопотребителей в г. Минске (2019 г.)

Figure 3. - The structure of the marital status of drug users in Minsk (2019)

(софоосбувир, софосбувир/ледипасвир, софосбувир/велпатасвир) [9-14]. Применение противовирусной терапии ВГС на фоне ЗТМ не требует коррекции доз метадона у участников программы, что может способствовать приверженности к заместительной терапии и к препаратам, используемых для лечения ВГС.

\section{Выводы}

На территории г. Минска более половины состоящих на учете наркопотребителей страдают от инъекционного употребления опиоидов. В возрастной структуре наркопотребителей наибольший удельный вес приходится на возраст 21-35 лет. Наибольшее количество наркоманов как в Республике Беларусь, так и в г. Минске, имеют среднее образование. В социальной структуре ПИН преобладают работающие лица и безработные старше 20 лет. Анализ семейного положения наркопотребителей показал, что более половины из них не состоят в официальных отношениях (холост/не замужем).

Численность участников программы ЗТМ в 2015-2019 гг. росла и достигла 161 чел. (2018 г.). Среди лиц, принимающих ЗТМ, отмечался также достоверный рост удельного веса ВИЧ-позитивных участников программы. Среди данной категории участников программы возросла доля лиц, принимающих АРТ (до 100,00\% в 2019 г.). Таким образом, установлено достоверное увеличение приверженности ВИЧ-инфицированных участников программы к приему АРТ.

Удельный вес ВИЧ-позитивных участников программы, коинфицированных ВГС, составил $100,00 \%$. Отсутствие воздействия противовирусной терапии ВГС ЛС прямого действия на фармакокинетику и фармакодинамику метадона может способствовать приверженности к заместительной терапии. 


\section{References}

1. United Nations. World drug report 2019 [Internet]. Available from: https://wdr.unodc.org/wdr2019/prelaunch/WDR2019_ B1 R.pdf.

2. Harm Reduction International. The Global State of Harm Reduction 2018 [Internet]. Available from: https://www.hri. global/files/2019/02/05/global-state-harm-reduction-2018. pdf.

3. Vinnickaja AG, Razvodovskij JuE, Lelevich VV. Ocenka chislennosti inekcionnyh potrebitelej narkotikov v Belarusi $\mathrm{s}$ ispolzovaniem metoda povtornogo zahvata [Estimating the number of injecting drug users in Belarus using the recapture method]. Voprosy narkologii. 2011;(5):46-50. (Russian).

4. Statkevich I, Samarina O, Truhan L, Pechko T, Pospelova V, KonojkoT, Ryzhkovskaja Ju, Goncharova S, Moskaleva I, Martynchik D. Snizhenie vreda: argumenty v polzu strategicheskih investicij. Nacionalnyj otchet Respubliki Belarus. Minsk; 2015. 61 p. (Russian).

5. Fisenko EG. Rasprostranenie VICh i parenteralnyh gepatitov sredi kljuchevyh grupp naselenija s vysokim riskom inficirovanija VICh. In: Parenteralnye virusnye infekcii: sovremennye vozmozhnosti diagnostiki i lechenija. Materialy Respublikanskogo nauchno-prakticheskogo seminara s mezhdunarodnym uchastiem; 2019 Sent. 26; Minsk. Minsk; 2019. (Russian).

6. Ugolovnyj kodeks Respubliki Belarus (Jul. 9, 1999, No. 275-Z). S izmenenijami i dopolnenijami (Jul. 17, 2018 No. 131-Z). Tekst po sostojaniju na 18 Jun. 2019. Minsk: Akademija MVD; 2019. 239 p. (Russian).

7. Grankov VI. VICh i parenteralnye virusnye gepatity v Evropejskom regione VOZ: vyzovy i perspektivy [HIV and parenteral viral hepatitis in the WHO European Region: challenges and prospects]. In: Parenteralnye virusnye in-

Конфликт интересов. Авторы заявляют об отсутствии конфоликта интересов.

Финансирование. Исследование проведено без спонсорской поддержки.

Соответствие принципам этики. Исследование одобрено локальным этическим комитетом.

Сведения об авторах:

Шилова Маргарита Александровна, к.м.н., доцент; Белорусский государственный медицинский университет; e-mail: makluk.sasha@gmail.com; ORCID: 0000-0002-2365-213

Абрамович Андрей Владимирович; Городской клинический наркологический диспансер, г. Минск; e-mail: andrey.abramovich1989@yandex.by

Вальчук Ирина Николаевна, канд. мед. наук, доц.; Белорусский государственный медицинский университет; e-mail: irina.valchuk@tut.by

Доценко Марина Леонидовна, д-р мед. наук, проф.; Белорусский государственный медицинский университет; e-mail: mar dots@mail.ru

Чистенко Григорий Николаевич, д-р мед. наук, проф.; Белорусский государственный медицинский университет; e-mail: chistenko@rambler.ru

Жаворонок Сергей Владимирович, д-р мед. наук, проф.; Белорусский государственный медицинский университет; e-mail: zhavoronok.S@mail.ru fekcii: sovremennye vozmozhnosti diagnostiki i lechenija. Materialy Respublikanskogo nauchno-prakticheskogo seminara s mezhdunarodnym uchastiem; 2019 Sent. 26; Minsk. Minsk; 2019. (Russian).

8. EACS. Guidelines - European AIDS Clinical Society Version 10.0. November 2019 [Internet]. Available from: https://www.eacsociety.org/files/2019_guidelines-10.0_final.pdf.

9. Epclusa. Prescribing Information, Gilead Science Inc November 2019 [Internet]. Available from: https://www.gilead.com/-/media/files/pdfs/medicines/liver-disease/epclusa/ epclusa pi.pdf.

10. Harvoni. Summary of Product Characteristics, Gilead Sciences Ltd. August 2019 [Internet]. Available from: https:// www.gilead.com/-/media/files/pdfs/medicines/liver-disease/ harvoni/harvoni_pi.pdf.

11. Harvoni. Prescribing Information, Gilead Sciences Inc. August 2019 [Internet]. Available from: https://www.medicines.org.uk/emc/product/3461/smpc.

12. Denning JM. Lack of effect of the nucleotide analog polymerase inhibitor PSI-7977 on methadone pharmacokinetics and pharmacodynamics. Hepatology. 2011;54(4):372.

13. Sovaldi. Summary of Product Characteristics, Gilead Sciences Inc. January 2014 [Internet]. Available from: https: //www.gilead.com/news-and-press/press-room/press-releases/2014/1/european-commission-grants-marketing-authorization-for-gileads-sovaldi-sofosbuvir-for-the-treatment-of-chronic-hepatitis-c-infection.

14. Sovaldi. Prescribing Information, Gilead Sciences Ltd. December 2013 [Internet]. Available from: https://www. medicines.org.uk/emc/product/5247/smpc.

Conflict of interest. The authors declare no conflict of interest.

Financing. The study was performed without external funding.

Conformity with the principles of ethics. The study was approved by the local ethics committee.

Information about authors:

Shylava Marharyta Aleksandrovna, PhD (Medicine), Associate Professor; Belarusian State Medical University; e-mail: makluk.sasha@gmail.com; ORCID: 0000-0002-2365-213

Abramovich Andrey Vladimirovich; City Clinical Narcological Dispensary, Minsk; e-mail: andrey.abramovich1989@yandex.by Valchuk Irina Nikolaevna, PhD (Medicine), Associate Professor; Belarusian State Medical University; e-mail: irina.valchuk@tut.by

Dotsenko Marina Leonidovna, PhD, MD (Medicine) Professor; Belarusian State Medical University; e-mail: mardots@mail.ru

Chistenko Grigory Nikolaevich, PhD, MD (Medicine), Professor; Belarusian State Medical University; e-mail: chistenko@rambler.ru

Zhavoronok Sergey Vladimirovich, PhD, MD (Medicine), Professor; Belarusian State Medical University; e-mail: zhavoronok.S@mail.ru 